\title{
Jacques Rancière. Contra-historias estéticas
}

\author{
Jacques Rancière. Aesthetic Counter-Histories
}

FERNANDO INFANTE DEL ROSAL*

Resumen: Este artículo se plantea definir en qué medida la estética de Jacques Rancière constituye un programa a seguir, un nuevo modo de reflexión estética dedicado tanto a la revisión de la historia del arte moderno como a la autocomprensión de la estética. Para ello, se centra en el análisis de la reescritura de la modernidad artística emprendida por el filósofo francés señalando cuáles son sus ejes conceptuales y sus herramientas. Por otra parte, se propone la tesis de que la estética, como formuladora en términos comprensibles del "régimen de identificación del arte", está determinada a convertir sus conceptos en valores.

Palabras clave: Arte moderno, emancipación, programa estético, conceptos estéticos, valores estéticos

\begin{abstract}
This paper aims to define terms in which the aesthetic thought of Jacques Rancière is a program to follow, a new mode of aesthetic reflection dedicated to both, reviewing the history of modern art and self-understanding of aesthetics. For that, this article focuses on analysing the rewriting of the artistic modernity undertaken by Rancière, noting what his conceptual axes and tools are. Furthermore, proposing the thesis that the aesthetic, as formulated in understandable terms in the "regime of identification of art", is determined to turn its concepts into values.
\end{abstract}

Keywords: Modern Art, emancipation, aesthetic program, aesthetic concepts, aesthetic values

\section{Contra-historias de la Modernidad y del modernismo}

Una de las contribuciones más significativas de Rancière al pensamiento estético vigente es haber replanteado las relaciones entre la estética y la historia escrita del arte moderno. Una importante parte de su crítica se ha centrado en la denuncia de los relatos vencedores elaborados, por una parte, por la estética moderna idealista y post-idealista, y, por otra, por la historia del arte. Estos relatos son los propios de la Modernidad, como paradigma filosófico, y del modernismo, como paradigma de la historia y la crítica de arte. Ambos relatos se

Fecha de recepción: 08/04/2015. Fecha de aceptación: 21/01/2016.

* Profesor del Departamento de Estética e Historia de la Filosofía de la Universidad de Sevilla finfante@us.es Sus líneas de investigación son Estética de la recepción, Filosofía de las emociones: simpatía, empatía e identificación, y Autonomía estética y arte de masas. Publicaciones recientes: "Miedo, conciencia, cerebro. Las experiencias del temor en relación al tiempo y la identidad", en Fedro. Revista de estética y teoría de las artes, 2015, n. 15, pp. 2-43; "Consideraciones analíticas sobre la idea de sublimación en Freud”, en Romero de Solís, D. y Murcia Serrano, I. (Coords.): En ningún Lugar. El paisaje y lo sublime. Universidad de Sevilla, 2015, pp. 230-272. 
caracterizan por haber situado en el centro del arte y de la estética los valores de libertad, autonomía y especificidad, subestimando o excluyendo con frecuencia, en su hacer teórico, aquellas manifestaciones que no se ajustaban a simple vista a tales valores, aunque esta no fuera la realidad de la práctica artística ni de la experiencia estética modernas. Los posteriores movimientos de inclusión por parte del arte crítico y relacional y por la neoestética de lo sublime no son para Rancière sino formas de reparar aquella postura al tiempo que la consolidan.

El pensamiento de Rancière no pretende, sin embargo, oponerse simplemente a tales relatos vencedores, como hace Jean-Marie Schaeffer (2005 [2000]), o como simula hacer el arte relacional (Bourriaud, 2007). Para Rancière, los relatos moderno y posmoderno se equivocan en su determinación unívoca de la libertad, la autonomía y la especificidad de lo estético o del arte, aunque tal error está en cierto modo motivado por la contradicción inherente al "régimen estético de identificación del arte" (2014b [2000], 31), el régimen de comprensión y disfrute de lo artístico propio de la Modernidad. Esa contradicción o paradoja se manifiesta en los juegos expresivos autonomía/heteronomía, artístico/estético, arte/ no-arte, etc. La limitación de los relatos moderno y modernista estriba en que ninguno de ellos advierte tal contradicción fundante y en que solamente perciben como legítimo uno de los términos antagónicos. La estética ha contribuido a tales relatos y los ha asumido dejando atrás el juego de antagonismos que le es esencial como régimen de identificación del arte. Se trata, por tanto, de un error de autocomprensión por parte de la estética moderna y de un desajuste entre su paradigma y el relato que tal paradigma genera.

Según Rancière, el reto de la estética en la actualidad consiste en asumir tal desajuste y en abordar tal autocomprensión dando voz, voz filosófica y voz crítica, a otros hechos y a otras visiones que no han estado presentes en dichos relatos vencedores. Se trata de disentir de esas narraciones, que funcionan bajo la forma de una "visión consensual" $(2005,75)$, articulando otras, las crónicas de los vencidos, las de las artes segregadas, subestimadas, desechadas o rechazadas: el diseño, las artes decorativas, el reportaje, las variedades, etc. $\mathrm{Y}$, en cualquier caso, sin fomentar la oposición dialéctica entre vencedores y vencidos, sino haciendo manifiestas en el orden del pensamiento expreso unas realidades que han sido y son manifiestas en el orden sensible. En esta contribución presentaré de manera sistemática y crítica ese programa rancieriano (aunque él nunca lo presenta como tal), examinando la conveniencia y provecho de sus presupuestos a la hora de inaugurar una estética programática que sustituya a la estética normativa que el propio Rancière evidencia.

En una de sus últimas obras, Aisthesis. Escenas del régimen estético del arte (2014a [2011]), Rancière recupera la escritura de microrelatos históricos que abordó en La noche de los proletarios. Archivos del sueño obrero (2010c [1981]), consolidando una reescritura pluralista y disgregada de los relatos de la modernidad y del modernismo en el ámbito artístico y estético: "Es difícil comprender las revoluciones escenográficas del S. XX sin detenerse en las veladas transcurridas en el Funambules o el Folies-Bergère por esos poetas que ya nadie lee: Théophile Gautier o Théodore de Banville; percibir la 'espiritualidad' paradójica de las arquitecturas funcionalistas sin pasar por las ensoñaciones 'góticas' de Ruskin; hacer una historia más o menos exacta del paradigma modernista olvidando que Loïe Fuller y Charles Chaplin contribuyeron a dicho paradigma mucho más que Mondrian o Kandinsky, y la descendencia de Whitman tanto como la de Mallarmé” (2014a [2011], 13). 
Para Rancière, este ejercicio de apertura de la visión consensual constituye una "contrahistoria de la "modernidad artística" (Ibid) que replantea y cuestiona las "numerosas historias imaginarias de la 'modernidad' artística" (2014b [2000]), 27). En este punto es conveniente tener en cuenta el pensamiento sobre la historia que desarrolla Rancière, su particular filosofía de lo histórico. Para él, la historia, especialmente en la "edad de la historia y de la estética" (2013 [2012], 25), es algo de lo que participamos o que elaboramos de manera sensible. Más que en el relato escrito, la historia en la modernidad se desenvuelve a través de manifestaciones sensibles como las de la imagen fotográfica. "La historia - dice- es el tiempo en el que aquellos que no tienen derecho a ocupar el mismo lugar pueden ocupar la misma imagen. [...] No se trata de 'igualdad de condiciones' ante el objetivo. Se trata de las dos potestades a las que el objetivo obedece: la del operador y la del 'sujeto'. Se trata de un cierto reparto de la luz" (2013 [2012], 21). Podríamos pensar, por tanto, que los relatos de la modernidad y el modernismo sobreescriben con la palabra excluyente que pone a cada uno en su lugar la imagen comprensiva que los hace visibles.

Entre las expresiones que juegan un papel significativo en esa contra-historia que emprende Rancière se encuentra el diseño. El pensamiento estético y la historia del arte presentan con frecuencia al diseño como un ámbito que se ha nutrido y se nutre de las revoluciones que, según estas disciplinas, tuvieron lugar en el terreno de la pintura de caballete o de la escultura. Para Jacques Rancière, en cambio, el diseño juega un papel destacado en las transformaciones de lo sensible, lo estético y lo artístico que se operan en el paso del siglo XIX al XX. Es en la superficie del diseño y no en la superficie pictórica tradicional donde se inicia tal transformación (2011 [2003], 113-114); es en las nuevas relaciones entre el texto tipográfico y la imagen donde se produce un nuevo reparto de lo sensible (2014b [2000], 23); es en las artes decorativas y aplicadas donde se transmutan las categorías del arte (2014a [2011], 180). "Serán ante todo los artistas 'aplicados' — afirma-, los artistas deseosos de educar a la sociedad mediante la forma de los edificios y los objetos de uso, quienes lleven a la práctica el concepto de esa 'necesidad interior' o 'espiritualidad' que reivindicará Kandinsky y en la que tantos comentaristas verán el privilegio del arte puro y autónomo" (2014a [2011], 178). De igual manera, es la reflexión asociada al Arts and Crafts, por parte sobre todo de Ruskin, Wilde o Morris, y al resto de movimientos vinculados al arte aplicado la que instala los nuevos valores: "[...] es en la teorización de las artes aplicadas donde hay que buscar la génesis de las fórmulas que servirán para emblematizar la autonomía del arte" (2014a [2011], 180). Decorativismo, funcionalismo y vanguardia, usualmente enfrentados en la historia escrita del arte, encuentran en Rancière un juego de conexiones y continuidades que transforma por completo la visión más generalizada del arte moderno, como expondré más tarde. La de Rancière es, pues, una revisión de la historia del arte moderno realizada desde la estética, crítica no obstante con los desarrollos de ambas.

Rancière emprende esta contra-historia a la manera del maestro ignorante, eludiendo los grandes trazos y los grandes rótulos, partiendo de una exposición de escenas que en ningún caso presumen ser hechos depurados ${ }^{1}$. No se trata, por tanto, de escribir una Contra-Historia

1 Como dice González Panizo, "su modo de operar no es el de basarse en veredictos basados en posiciones apriorísticas, sino más bien aquel otro afanado en la construcción de la arqueología de nuestro presente, una topografía de potencialidades que mantienen su carácter siempre abierto de posibilidad" $(2013,28)$. 
con mayúsculas, un gran relato alternativo a los grandes relatos de la modernidad y del modernismo, sino de presentar ante un oyente des-figurado motivos particulares, motivos insidiosos que minan por simple acumulación toda la solidez de las grandes narraciones. De la vieja estética y la vieja historia del arte podría decirse lo mismo que del maestro obstinado: "Todo lo que pide el Viejo es que se le admitan sus negaciones y sus diferencias: esto no es, esto es otra cosa, esto es más, esto es menos. Y ya tiene bastante para erigir todos los tronos de la jerarquía de las inteligencias" (2010b [1987]). Por esta razón, el programa estético de Rancière es - como el de Jacotot, el educador revolucionario que le inspira su maestro ignorante - , un apunte de igualdad y de emancipación. Igualdad y emancipación que, en el terreno estético, desenmascaran a una estética, una crítica y una historia del arte ciertamente unilaterales.

\section{Autocomprensión de la estética}

Es innegable que Rancière emprende una crítica de la institución, de las instituciones del arte y la política como favorecedoras de un determinado espacio, así como una crítica de aquello que, oponiéndose supuestamente a ella, mantiene el statu quo, la configuración dominante o la "visión consensual", como sucede con las derivaciones del arte crítico y con el arte relacional (2012b [2004], 60). Pero Rancière no permanece en una simple crítica de la facticidad, en una censura del estado de las cosas. La crítica no garantiza ningún objetivo pragmático de transformación porque ella misma ha mostrado con frecuencia que no le resulta ajeno ni difícil pasar a formar parte de ese estado de las cosas. La crítica puede convertirse en institución, pero también la institución puede ser la plataforma de las transformaciones; por lo tanto, no es esta una manera de proceder apropiada. La propuesta consiste más bien en recuperar para lo visible aquellos momentos, aquellas escenas que son capaces de crear por su propia virtualidad distorsiones, interferencias e intersticios dentro de los grandes relatos.

Las formas teóricas y prácticas del arte y de la estética dominantes preservan una topografía que no hace sino consolidar los espacios de estos grandes relatos, así como los límites entre las prácticas artísticas o las fronteras entre aquellas manifestaciones que se consideran genuinamente artísticas y aquellas que no. Pero lo que existe más bien - incluso en la institución - es, como dice Rancière, "[...] una permeabilidad de las fronteras y una incertidumbre de las trayectorias, que tal vez tengan una importancia mayor que las escenificaciones canónicas de la relación entre el dentro y el fuera, lo legítimo y lo no legítimo" $(2005,74)$. Se trata, por tanto, de "Salir del simplista esquema espacio-político en términos de alto y de bajo, de dentro y de fuera" $(2005,76)$.

Para esto, Rancière esquiva, por una parte, el paradigma de los estudios culturales actuales, deudor tanto de los escritos de Dwight Macdonald y Raymond Williams, con su topografía de alta y baja cultura, como de la crítica de Clement Greenberg, con su canónica distinción entre Vanguardia y Kitsch (2002 [1936]); y se enfrenta, por otra parte, a las visiones modernas y modernitarias, que no hacen sino reforzar la frontera entre el arte y el no-arte, cuando es precisamente la unidad del arte y el no-arte lo que constituye este "régimen estético del arte" (2012b [2004], 49).

Se trata, por eso, de malentendidos de la teoría. Pero no porque tal teoría no se acerque a los hechos, a una supuesta experiencia artística y estética efectiva - como piensa Schaeffer (2005 [2000]) - , sino porque esa teoría no ha mirado en su propio interior, en su propio 
fondo. El problema de las teorías o visiones institucionalizadas y consensuales proviene, por una parte, del hecho de que estas operan en un nivel superficial asumiendo preconceptos y valores que no llegan a abordar problemáticamente, $\mathrm{y}$, por otra, de su inadecuada comprensión de la relación entre la teoría y la práctica, entre los conceptos y las experiencias sensibles. La teoría no es consciente de la contradicción instalada en el origen de la modernidad.

En la visión de Rancière, la estética excede el carácter de disciplina o de ámbito de la filosofía. Como tercer régimen de identificación del arte, conforma un universo de comprensión de lo artístico y de lo estético. Es, de hecho, el paradigma que ha generado las distinciones entre lo artístico y lo estético, entre el arte y el no-arte, entre la autonomía y la heteronomía, para aprehenderlas más tarde como categorías alternativas y terminar optando por una de ellas, ya no como categoría, sino como valor. De esta manera, se conforma una estética dominante que profesa su fe ante los valores del arte autónomo; que llega a hacer un uso peyorativo del término "estético" para referirse precisamente a aquello que no considera propiamente "artístico" (lo estético no-artístico); que, finalmente, se ausenta un tiempo de sus salones para alternar con las políticas inclusivas y de proximidad del arte a las que ciertamente protege de una heteronomía temeraria, etc. (Infante del Rosal, 2015). Esto ha generado numerosas paradojas y contradicciones en el seno de la reflexión estética, especialmente desde los años treinta hasta nuestros días. Aunque Rancière no lo expresa de esta manera, podría decirse que el problema fundamental de la estética radica en el hecho de haber convertido sus conceptos en valores, de haber olvidado que los juegos dialécticos de lo artístico y lo estético, el arte y el no arte, o la autonomía y la heteronomía, constituyen sus esquemas básicos, aquello que articula su comprensión y disfrute del arte y de la experiencia estética (distinción esta únicamente comprensible dentro del régimen estético mismo).

En este sentido, la crítica de Rancière a la estética coincide con la crítica hecha desde la filosofía analítica (Schaeffer, 2005 [2000]) o desde la teoría marxista (Bürger, 1996 [1983]). Como estas, la de Rancière se centra en el carácter axiológicamente sesgado que asume la estética ejercida en el ámbito institucional, pero se diferencia radicalmente de tales desaprobaciones al asumir que los términos alternativos de autonomía y heteronomía son igualmente constitutivos del "régimen estético del arte" (2012b [2004], 44; 84-85), de la misma forma que la pureza y la impureza, la libertad y la ausencia de esta, la esencialidad y la inesencialidad, la propiedad y la impropiedad, el arte y el no-arte. La alternativa y la paradoja son, ya lo hemos visto, inherentes al régimen estético del arte, porque es tal régimen el que genera y formula los opuestos.

Rancière, por tanto, no propone, como los críticos de la estética moderna o idealista, abandonar su ámbito como si de una disciplina o discurso privativo se tratase. Esto resulta imposible, porque la estética como régimen establece justamente los modos de comprensión y sensibilidad que dan sentido a los conceptos y valores con los que se la quiere impugnar. El reproche del filósofo francés va dirigido solamente a aquellos que, como Greenberg han contribuido a convertir ciertos conceptos en valores señalándolos, además, como ámbitos exclusivos de una propiedad del arte y de lo estético, y a aquellos que, como Lyotard, Badiou o Schaeffer, critican a la estética como disciplina ignorando que se trata, a juicio de Rancière, de algo más que un ámbito doctrinario.

Por tanto, las estrategias de inclusión - de las artes heterónomas en el cerco del gran arte, como hace Badiou con el cine (2009 [1998]) -, de recuperación — de la experiencia 
estética ajena a la acción artística y a los valores del genio, como la emprendida por Schaeffer-, o de fusión - del arte y el no arte, a la manera del arte relacional -, no hacen sino consolidar la visión que quisieran abolir.

Rancière ha subrayado el carácter autorreflexivo y autocrítico de la estética, rasgo localizable desde sus primeras formulaciones explícitas por parte de Kant y de Schiller, pero ha resaltado también la dificultad que la estética tiene en la actualidad para autocomprenderse y para entender las problemáticas relaciones con el arte que en ocasiones asume. El desconcierto de la estética - desconcierto en sus dos acepciones más comunes - se debe en gran parte al hecho de que ella misma ha dejado de verse como generadora y articuladora de los conceptos antitéticos. Al haber contribuido a confirmar algunos de ellos como ideales o valores, ha olvidado que la paradoja o la alternativa, y no solo una de sus partes, es lo constituyente de su visión. Por eso, no se trata de convertir ahora en valor la heteronomía, el no-arte, o la cercanía de las artes aplicadas, porque esto implica permanecer en el mismo error. Es, por tanto, el sesgo axiológico de la estética hegemónica, así como su compromiso con los proyectos de emancipación o de superación del arte lo que le hace olvidar la constitución paradójica de su propio régimen, en tanto que "Este ha vivido siempre de la tensión de los contrarios" (2012b [2004], 55), y en tanto que, "En este régimen, el arte aparece identificado como concepto específico. Pero lo es por la defección misma de todo criterio capaz de separar sus maneras de hacer de otras maneras de hacer". (2012b [2004], 83).

Son los discursos de la crítica, la historia del arte, el comisariado artístico, la propia práctica artística y la estética los que han contribuido a la idealización y axiologización de los conceptos estéticos, aunque sea la estética filosófica la que los formuló de manera sistemática. Por tanto, la conversión de conceptos en valores (y esta, recuerdo, no es una tesis de Rancière), no es asunto exclusivo de la estética como disciplina filosófica o dominio académico. Es, por ejemplo, un crítico de arte - Greenberg - quien ejerce de gran teórico del modernismo, y de manera más clara aún, si cabe, que el propio Adorno; o un profesional de la curatoría y la museología contemporánea como Bourriaud, quien formula los términos actuales de la relación entre arte y no-arte. No obstante, por una parte, es fácil aceptar que la estética juega el papel principal en la transformación de la axiología moderna, ya que como dominio de la filosofía moderna es la encargada de pensar y formular las nociones y relaciones de un nuevo régimen de comprensión, disfrute y sensibilidad; pero, por otra parte, en el sistema kantiano y en todo el proyecto ilustrado, tales nociones y relaciones nacen ya con el cuño del valor. Lo que hace que el estatuto de la estética filosófica sea particular es que ella recibe devueltas las reelaboraciones que de sus propios conceptos hacen el resto de teorías y prácticas artísticas y estéticas. Esto último puede decirse de todo dominio filosófico respecto de otras teorías y de otras prácticas, por supuesto, pero reconozcamos la singularidad de las experiencias estéticas y artísticas, así como la estrecha relación entre la idea de historia del arte y el pensamiento estético (Hegel está ahí para demostrarlo).

\section{Una estética de la igualdad frente a la estética de la libertad}

El relato estético de la Modernidad y el modernismo está guiado por un valor fundamental ajeno al arte: la libertad. Según Hegel, la Historia es la historia de la libertad, lo que implica que todo relato es un relato de emancipación. La estética idealista fundamenta los 
términos del relato de la autonomía y la soberanía del arte al fijar su vector más determinante. Pero es justamente la cualidad de valor de la libertad la que conduce, a mi juicio, a la transformación de los conceptos estéticos en valores. Así sucede con las ideas de lo sublime, de desinterés, de extrañamiento y de distancia estética, que, al ligarse al ideal de la libertad, dejan atrás su carácter de factor artístico, de cualidad de la obra o la acción, de principio artístico incluso, para pasar a convertirse definitivamente en valores de clase.

Rancière identifica la estética de lo sublime conservada en nuestros días con la actitud de la mayor parte de filósofos e historiadores del arte, que se guía por "una potencia liberadora del arte ligada a su distancia con respecto a la experiencia ordinaria" (2012b [2004], 31). Frente a ella se sitúa la "estética relacional" —en alusión a la expresión "arte relacional" de Bourriaud - , cercana a las políticas de "proximidad" predominantes. Ambas son para el pensador francés actitudes características del momento presente $\mathrm{y}$, según veremos, ciertamente complementarias.

Al margen de la libertad como valor característico, tanto de la estética idealista de Kant, Schiller y Hegel, como de la visión modernista del arte de vanguardia, Rancière recupera una perspectiva basada en la igualdad. Podría pensarse que operar así no es sino reemplazar un valor por otro - la libertad por la igualdad - , con lo cual no se eliminaría el carácter axiológico de la estética, pero Rancière se cuida de presentar la igualdad como un propósito. Se limita a describirla como una realidad que hay que reconocer. El proyecto de la emancipación es entonces un proyecto de reconocimiento, no de conquista.

Por otra parte, esta igualdad de la que habla Rancière, que es la igualdad de "cualquiera con cualquiera" (2012a [1996], 50), es ajena a los discursos consensuales del igualitarismo. Su función en el programa de la estética es deshacer los relatos de la modernidad y del modernismo, que se articulaban a partir de la libertad como valor y, por tanto, con la autonomía como ideal, como vector de la historia y el desarrollo del arte. La igualdad propuesta no constituye, pues, un objetivo, sino un rasgo a recuperar: "La igualdad no es un dato que la política aplica, una esencia que encarna la ley ni una meta que se propone alcanzar. No es más que una presuposición que debe discernirse en las prácticas que la ponen en acción" (2012a [1996], 49). La estética, en cierto modo, al perseguir la libertad vacía y formal de las expresiones que pueden alcanzarla - las del arte autónomo - habría traicionado la igualdad con la que se formula el mismo régimen estético del arte, la igualdad que está en su propia constitución. Al haberse preocupado, diríamos, de la libertad de unos, descuidó la igualdad de todos.

Ante el "reparto de lo sensible" (2014b [2000]) que la estética se encarga de expresar, la igualdad programada constituye un movimiento regresivo o involucionista en tanto que de lo que se trata es solamente de asumir la desespecificación, la desdefinición, la desidentificación y la indistinción del arte en el régimen estético. Tal indistinción es inherente a la estética como régimen de identificación del arte. Su identificación del arte consiste en "una igualdad inédita" (2012b [2004], 24) entre el arte y el no-arte, entre lo sublime y lo cotidiano, entre el saber hacer y el "no importa qué ni cómo", entre la naturaleza humana y la naturaleza social, etc. Es decir, su identificación del arte consiste en una desidentificación del arte, en tanto que este ya no será más el conjunto de modos de hacer, ni se basará necesariamente en la pregunta ética, ni en ese principio de división de las actividades humanas llamado mimesis, lo que era característico de los regímenes de identificación del arte precedentes. En tanto que el 
régimen estético "Afirma la absoluta singularidad del arte y destruye al mismo tiempo todo criterio pragmático de esta singularidad” (2014b [2000], 36), establece la igualdad como su presupuesto básico, igualdad que concierne fundamentalmente a los criterios antagónicos. Es cierto devenir histórico de la estética el que contradice dicha igualdad al tomar parte por uno de los criterios y al señalarlo como legítimo.

Este punto de vista lleva al pensador francés a negar que exista una ruptura posmoderna: todos los supuestos giros contemporáneos están articulados dentro del mismo régimen estético. Esto es enormemente relevante porque viene a decir que no hay discontinuidad significativa entre el arte moderno y el arte contemporáneo y posmoderno, a diferencia de visiones más establecidas como la de Danto (2013 [1997]); pero también que no hay diferencia sustancial entre la estética del momento idealista y la del momento contemporáneo. Esto puede afirmarse, evidentemente, solo en lo que al fondo de tales momentos se refiere y no a las manifestaciones singulares. Rancière habla de los parámetros propios de un paradigma, no de las maneras en que tal paradigma o régimen se conforma: un determinado "reparto de lo sensible" - precisaré esta expresión más tarde - puede hacerse notar en discursos y en imágenes aparentemente diferentes (aunque esto no debe entenderse en términos de una distinción entre realidad y apariencia, o entre contenido y forma).

De esta manera, las políticas artísticas integradoras, socializadoras o críticas no rompen con nada, porque no escapan a los términos que conforman su paradigma. Y por estas razones, la práctica estética de la igualdad no debe basarse en la mera inclusión. No se trata de incorporar lo exotérico al discurso principal, al relato dominante, sino de hallar los rasgos potenciales de las formas de expresión que han quedado fuera. El mismo estilo concreto y preciso de investigación que guió a Rancière en La noche de los proletarios o en su trabajo sobre los poetas obreros de la Francia de Luis Felipe (1983, 31-47) se prolonga en su análisis de las transformaciones de lo sensible producidas desde finales del siglo XIX en todos aquellos momentos o espacios relegados al margen de las narraciones hegemónicas. La igualdad no es, por tanto, asimilación al lugar del consenso. Se trata de "[...] explorar las virtualidades de fórmulas artísticas nuevas incluidas en sus prácticas. [...] Consiste en extraer competencias de ellas mismas más que en decretar su igual dignidad" $(2005,76)$. El proyecto de Rancière no coloca, como decía antes, un ideal y un valor en el término de un camino con un programa para alcanzarlos. El proyecto estético sugerido es más bien un programa de recuperación, o, como suele decirse, de puesta en valor.

Sobre el ambiguo o falso igualitarismo del arte crítico tardío y de las políticas artísticas de éxito escribe Rancière: "Esta [la idea consensual] consagra el arte a funciones de reconciliación entre arte y no arte, y de rehabilitación de las artes y culturas infravaloradas, a fin de restaurar el vínculo social supuestamente roto. Esta voluntad puede adquirir la forma de una marca de fábrica que decreta el final oficial de las jerarquías de las artes y de las culturas. Reconoce como artistas, en plano de igualdad con los grandes representantes del 'gran arte' del pasado, al modisto de alta costura y al rapero de barrio. Sin embargo, esta manera de repartir igualitariamente la marca del arte y de reconocer la pluralidad de las culturas es también una manera de poner a cada cual en su lugar" (2005, 74-75). Los discursos expositivos y museísticos dominantes, los del arte relacional, presumen en ocasiones de haber soltado amarras respecto a la estética filosófica como discurso fundante presentándose como alternativa a la estrategia de lo sublime, pero en la realidad siguen anclados por un discurso 
firme que ha racionalizado y fundamentado la libertad con la que operan, el de la misma estética de lo sublime. En esto coinciden, a mi entender, aquellas derivaciones que Rancière entiende como las "dos grandes concepciones de un presente 'post-utópico' del arte" (2012b [2004], 28), la relacional y la sublime. Toda virtual posición antiestética, venga del arte o de la estética misma, no hace sino reafirmar el esquema de la estética como régimen.

La igualdad impostada de las políticas artísticas en la actualidad, legitimada por la fundamentación de la estética sublime, confirma la acción de la institución, del sistema de legitimaciones que Rancière llama policía (2012a [1996], 43), porque "La igualdad se transforma en su contrario a partir del momento en que quiere inscribirse en un lugar de la organización social y estatal. Es así como la emancipación intelectual no puede institucionalizarse sin convertirse en instrucción del pueblo, es decir, organización de su minoría perpetua" (2012a [1996], 50).

Rancière no adopta, por tanto, una posición extensional respecto a la estética. Al destacar la relevancia de las artes y los formatos menores para las transformaciones modernas del arte y al constatar la igualdad establecida por la estética, no pretende extender la frontera del arte ni abrir sus puertas para cercar lo que antes estaba fuera, como reprocha a Badiou. Su propuesta es precisamente la de "deshacer las certidumbres del lugar" (1991, 9), como hace la mirada del extranjero.

Por último, se habrá podido notar que la igualdad mencionada tiene dos referentes principales: la igualdad de los individuos y la igualdad de las manifestaciones artísticas. Ambos referentes están, no obstante, unidos porque "La igualdad de todos los sujetos es la negación de toda relación de necesidad entre una forma y un contenido determinado" (2014b [2000], 22). La igualdad defendida por el proyecto ilustrado coincide con la descomposición de las antiguas diferencias en los modos de sensibilidad; la igualdad moderna se simboliza y a la vez coincide con un nuevo "reparto de lo sensible" (2014b [2000]). Este último, que es, sin duda, el principal concepto estético de Rancière, se define como "ese sistema de evidencias sensibles que permite ver [o que hace visible] al mismo tiempo la existencia de un común y los recortes que definen sus lugares y partes respectivas" (2014b [2000], 19) [acotación mía]; es la distribución de lugares que manifiesta quién puede tener parte en lo común según su ocupación, y según el tiempo y el espacio en el que ejerce su actividad. El reparto de lo sensible señala un común repartido al tiempo que fija partes exclusivas. En el caso del régimen estético, tal reparto de lo sensible favorece, podríamos decir, una igualdad que se hace visible; pero el discurso y el relato de la modernidad, el mismo discurso y relato estético, aun habiendo formulado de manera comprensible los términos de ese reparto, termina traicionándolo. Esto puede deberse a que la función de la primera estética no se limitaba a la formulación inteligible de las transformaciones: más apremiante resultaba su compromiso con el proyecto emancipatorio de los sujetos. Este compromiso es el que hace que sus conceptos se cambien a valores desde su misma formulación inicial.

\section{Escritura de la contra-historia}

En la manera en que Rancière aborda las contra-historias, los microrelatos de los vencidos, reconocemos una serie de herramientas que el pensador ha ido formulando en el conjunto de sus escritos. Para poder precisar en qué medida el pensamiento estético de Rancière 
puede ser concebido como un programa a seguir, señalaré aquí de manera sucinta cuáles son esos conceptos operativos y la manera en la que articulan la estrategia de la igualdad.

\subsection{Los conceptos y las reconfiguraciones de la experiencia}

A grandes rasgos, el método de Rancière se basa en una inducción que altera el trabajo de deducción característico de la estética y la historia del arte modernas. Su estilo permanece cercano a la descripción y al detalle, y la interpretación y la evaluación no se introducen nunca como preámbulos de demostraciones subsecuentes. Con todo, Rancière es sobradamente sabio y versado como para llegar a confundir las cosas reales con la realidad de las cosas. Este tipo de observación y de predisposición le lleva a afirmar que los conceptos modernos de la estética no son sino formulaciones inteligibles de cambios que operan en la experiencia sensible: "El arte comenzó a existir en Occidente como tal cuando esta jerarquía de las formas de vida empezó a vacilar. Las condiciones de este surgimiento no se deducen de un concepto general del arte o la belleza fundado en un pensamiento global del hombre o el mundo, el sujeto o el ser. Tales conceptos dependen en sí mismos de una mutación de las formas de experiencia sensible y de las maneras de percibir y ser afectado. Formulan un modo de inteligibilidad de estas reconfiguraciones de la experiencia" (2014a [2011], 9). Resulta, por tanto, fundamental la relación existente entre lo que Rancière llama modos de inteligibilidad, es decir, los conceptos, y las reconfiguraciones de la experiencia sensible. Las correspondencias entre ambos constituyen la relación fundamental entre estética y política, porque en la base de toda política hay una estética. "Reparto de lo sensible" es la expresión de esa relación.

Las reconfiguraciones producidas en el reparto de lo sensible, las "mutaciones del tejido sensible" (2014a [2011], 11) no son acontecimientos surgidos a partir de un concepto, son indisociables de los regímenes de inteligibilidad que los hacen visibles y, al mismo tiempo, "Estas metamorfosis no son fantasías individuales sino la lógica de este régimen de la percepción, afección y pensamiento que he propuesto llamar "régimen estético del arte"" (2014a [2011], 12). Nótese que aquí la palabra "lógica" encierra un aspecto fundamental: un régimen de sensibilidad, aun siendo una configuración histórica, encierra una estructura de relaciones, un esquema. Rancière no ha llegado a medirse del todo con Hegel, pero es evidente que esa es una tarea pendiente. Aceptemos por ahora simplemente que Rancière adopta tan solo una lógica interna a cada régimen sin abordar con profundidad qué hace que se produzca el salto de cualidad de un régimen a otro.

Existen dos procesos que describen las reconfiguraciones que se producen dentro de un régimen: la subjetivación estética, definida como "diversidad imprevisible de maneras en que no importa qué individuos pueden entrar en el universo de la experiencia estética, a través de negociaciones concretas de la relación entre proximidad y distancia" $(2005,72$; cfr. 2012a [1996], 52). Y la objetivación estética, el "proceso aleatorio que transfiere formas de entretenimiento o espacios de diversión al dominio del arte" $(2005,73)$.

\subsection{Disenso y cuestionamiento frente a una crítica que es consensual}

Por otra parte, Rancière introduce las ideas de disenso y de cuestionamiento como factores fundamentales de esa contra-historia. El disenso estético $(2005,72)$ altera la "visión con- 
sensual" $(2005,75)$, destacando el conflicto y la heterogeneidad: "La cuestión no consiste en aproximar los espacios del arte al no arte y a los excluidos del arte. La cuestión consiste en utilizar la extraterritorialidad misma de esos espacios para descubrir nuevos disensos, nuevas maneras de luchar contra la distribución consensual de competencias, de espacios y de funciones" $(2005,76)$.

No se trata entonces de ofrecer reconocimiento de lo ya visible, sino experiencias a partir de su mismo "cuestionamiento". Este cuestionamiento no es ya el extrañamiento (Entfremdung) de Hegel (2006 [1807], 587-588), ni la distancia psíquica de Bullough (1997 [1912]), ni el efecto de distanciamiento (Verfremdungseffekt) de Brecht (2004 [1957]), porque ya no se propone tanto encontrar una cualidad alternativa, como deshacer certidumbres. Al fin y al cabo, como afirmé antes, el extrañamiento y el distanciamiento, como conceptos estéticos de primer orden, habían sido impregnados del valor de la libertad convirtiéndose ellos mismos en valores estéticos y artísticos.

El cuestionamiento se une a la igualdad, que no es permanecer en lo igual, o colocarlo todo en lo idéntico reconocido como digno. Esta igualdad no está vinculada con la identidad, que presupone un "cada uno en su lugar", ni con la identificación-reconocimiento, que, fingiendo movimiento, existe precisamente por ese mismo principio de inmovilidad. La ficción de la identificación y del reconocimiento fomenta el orden dado, pero también la distancia estética moderna y la distancia brechtiana promueven ese orden al normativizarse. A esto, Rancière opone otra ficción y otra distancia estética: "Los espacios del arte pueden servir para este cuestionamiento si se dedican menos a los estereotipos de la denuncia automática o a las facilidades de la parodia indeterminada que a la producción de dispositivos de ficción nuevos" $(2005,77)$. En lo que Rancière sí es abiertamente antihegeliano es en su rechazo de la idea de un camino hacia la autoconciencia y el encuentro consigo mismo del arte. Tal camino presupone una identidad y un "propio del arte" que, como hizo el modernismo, se interpreta siempre de manera partidista hacia uno de los conceptos antagónicos, como hemos visto. Es presumible, por tanto, que la autorreflexividad del arte, la autorreferencia y, por supuesto, la parodia, le parezcan desencaminados.

Aún así, la propuesta de Rancière no es del todo contraria a la máxima de Adorno: "Pero también debe [el arte] reafirmar la distancia estética, plantearse, frente a las pedagogías de la accesibilidad y los mercados de la diversidad alimentados por la lógica consensual, como un espacio de originalidad, de extraterritorialidad donde los dispositivos sensibles específicos borran las marcas de lo próximo y de lo distante, de lo común y de lo diferente" $(2005,78)$. Rancière no es crítico con el arte contemporáneo por ser autónomo; tampoco lo es con ninguno de los conceptos estéticos - lo sublime, la distancia estética, etc. - , su discurso no se basa en la contraposición de los artistas autónomos con los aplicados, ni entre el arte musealista y el arte funcional; no juega a la oposición que hace que tengan sentido precisamente las políticas de inclusión o extensión del arte relacional. La igualdad permite que el espíritu sople donde quiere, pero esto no supone una neutralización, ni una disolución del arte o de su efecto, sino todo lo contrario. La igualdad hace que las virtualidades de las formas que han quedado relegadas en el reparto se hagan visibles y que las que ya lo eran escapen a la policía de unas instituciones - el arte, la historia, la crítica, la estética - que se han traicionado a sí mismas. El arte tiene la capacidad de producir el consenso haciendo visible lo sensible común, y el disenso, haciendo visibles las partes exclusivas. Pero el arte 
crítico institucionalizado rehace constantemente el esquema de la desigualdad al empeñarse en "mostrar al espectador lo que no sabe ver y de avergonzarlo de lo que no quiere ver, aunque el dispositivo crítico se presente a su vez como una mercancía de lujo perteneciente a la lógica que él mismo denuncia" (2010a [2008], 35).

\subsection{Continuidad y discontinuidades}

Frente a la linealidad o la vectoricidad planteada por las visiones hegelianas, Rancière concibe permanentes transformaciones (reconfiguraciones, mutaciones o metamorfosis) que no responden a ese resuelto vector. Sin embargo, a pesar de estas constantes discontinuidades, una de las mayores aportaciones de Rancière a la reescritura de la historia del arte moderno ha sido precisamente la de encontrar la continuidad entre tres momentos que los relatos moderno y modernista han entendido siempre como desacordes: primero, el marco precedente a las vanguardias de recuperación de lo artesanal, lo utilitario y lo cotidiano en los movimientos Arts and Crafts, Art Nouveau y otras corrientes asociadas a las artes decorativas; segundo, el contexto de las propias vanguardias; y tercero, el marco de los movimientos funcionalistas, desde el Werkbund a la Bauhaus (2012b [2004], 51-52). De esta forma, lo que el relato vencedor había asumido como una gran discontinuidad y ruptura - la vanguardia - aparece ahora como algo encadenado al marco precedente, en el que ya se habían producido algunas de las transformaciones más significativas; y, a la inversa, en los episodios percibidos con anterioridad como continuistas con la tradición (todos los planteamientos de Ruskin, Morris y las artes decorativas), aparece ahora el signo del auténtico cambio. Y, de igual manera, el funcionalismo moderno está imbricado con los otros dos contextos. De hecho "Son también los mismos principios y los mismos pensadores de la forma artística - afirma - quienes permiten teorizar la abstracción pictórica y el diseño funcional" (2011 [2003]: 111).

Esta continuidad no es señalada, sin embargo, en los términos de un análisis formalista, y tampoco lo es en cuanto al contenido. La continuidad que Rancière halla entre Mallarmé y Peter Behrens, por ejemplo, expresa muy bien el orden en el que Rancière se mueve, aquel en el que lo político y lo sensible constituyen una misma realidad (2011 [2003]: 102 y ss.).

Entre los pocos reproches emitidos por Rancière hallamos uno contra el desconocimiento por parte de quienes con una "doxa perezosa" (2014a [2011], 180) han contribuido al relato preponderante: "Adorno tiende a desconocer la genealogía paradójica que lleva de Ruskin al Werkbund y a la Bauhaus y, al mismo tiempo, el rol de los debates en torno a las artes aplicadas en la construcción de las categorías del modernismo artístico" (2014a [2011], 180).

Por otra parte, y como vimos anteriormente, tampoco la posmodernidad implica una discontinuidad significativa respecto al momento precedente: "No existe ruptura posmoderna. Existe una contradicción originaria y que actúa de manera incesante" (2012b [2004], 49). Los supuestos giros del arte contemporáneo y de la posmodernidad no son más que reformulaciones adscritas a esa contradicción originaria del régimen estético de identificación del arte.

\subsection{Emancipación y emancipaciones}

En la contra-historia es preciso tener presente la relación que existe, dentro del régimen estético, entre la emancipación de la humanidad y la emancipación del arte. A mi juicio, la 
modernidad y el modernismo han desarrollado tres sentidos fundamentales de la emancipación artística: la emancipación del arte como práctica independiente de otras prácticas y funcionalidades; la emancipación del sujeto creador y del sujeto receptor; y la emancipación del "detalle" artístico (Adorno y Horkheimer 2001 [1947], 170), del componente formal y material de cada arte. La estética moderna destaca el primer sentido, el arte moderno, el segundo, y la crítica modernista, el tercero. La emancipación o liberación del "detalle" - la pincelada, el color, la forma, el concepto, etc. - por parte de los sucesivos movimientos de pre-vanguardia y vanguardia, que destaca la visión modernista, sería la expresión sensible y formal de la emancipación de los artistas como sujetos libres y del arte como práctica igualmente libre. Pero en Rancière, lo sensible ya no hace referencia solamente al aspecto formal que, a su entender, subraya el modernismo; lo sensible es aquello en lo que se desenvuelven las tres emancipaciones, el espacio político en el que las condiciones del arte y sus manifestaciones se dan de acuerdo a un determinado reparto. Por eso Rancière se aleja tanto de las teorías sociales del arte como de las teorías formalistas. Precisamente porque la igualdad de los sujetos ha abolido las relaciones de necesidad entre formas y contenidos concretos, ambas teorías dejan de tener sentido, tanto juntas, como por separado. La teoría de Rancière, en tanto que parte de una nueva concepción de lo sensible, de una inédita relación entre estética y política, inaugura un nuevo modelo especulativo en el que han cambiado el método, los términos y hasta el objeto mismo.

Rancière ha afirmado recientemente (2012c) que la emancipación es una idea "huérfana" porque no sabemos a dónde nos conduce. La emancipación a la que se refiere Rancière tiene que ver con la asimilación crítica del marco sensible y con los modos de enriquecer o transformar tal marco sensible. Emancipación ya no es, como hemos visto, el curso hacia la libertad, sino disenso, extraterritorialidad y distorsión. No sabemos qué vendrá, pero sabemos que siempre es preciso mirarse desde fuera, abrirse para tomar conciencia del territorio, de lo "autóctono". Este abrirse no es entregarse a la novedad, categoría fundamental de lo moderno y de la que Adorno sentenciaba que era hermana de la muerte (2004 [1970], 36). El programa de Rancière, si lo es, no plantea ni un autoreconocerse en un propio del arte, ni un abrazar la novedad; ni un sustancialismo hegeliano, ni un formalismo abierto a la innovación vacía. Lo que se reconoce en el momento de la emancipación no es la supuesta propiedad del arte ni la extensión de su carne en lo nuevo; se reconoce que las oposiciones que están en juego pertenecen a la estructura de la dominación y de la sujeción, que son "alegorías encarnadas de la desigualdad" (2010a [2008]18). Además, tal emancipación no se produce en las actitudes extremas; antes bien, "Es un fenómeno que se desarrolla en los espacios intersticiales: los espacios del tiempo dividido y los de las fronteras inciertas entre los modos de vida y las culturas" (2010c [1981], 13).

\section{Estética programática que sustituye a una estética normativa}

Si la estética de Rancière es susceptible de convertirse en un programa que otros realicen junto a él, solo lo es en cuanto análisis crítico. El filósofo ha reconocido muchas veces que no cuenta con figuras o tipologías para la liberación. Su pensamiento no pretende descubrir ni prescribir recetas, pero también es evidente que no se formula para permanecer en la simple articulación de conceptos. En su propia concepción de la emancipación se incluye ya su 
motivación: se trata de reconocer las oposiciones, la contradicción de términos antagónicos del reparto sensible, su carácter de simbolización y a su vez de configuración de desigualdades, dejando espacio, abriendo fisuras, en el pensador, que es siempre el otro, el lector, el espectador. Esto puede hacerlo la política, puede hacerlo la estética y puede hacerlo el arte, cada uno en sus términos dentro del reparto de lo sensible que constituyen.

En este caso, la estética es la estética filosófica o, si se quiere, la estética académica, aunque su gestión de la emancipación supone también un reencuentro con la historia del arte y con la crítica. Todas las disciplinas del arte están enlazadas por los términos del mismo régimen estético.

A las tesis de Rancière expuestas he unido en estas páginas otra que considero complementaria: La estética moderna se consolida no solo como sistema de conceptos que hacen inteligible el nuevo régimen de sensibilidad y un nuevo reparto de lo sensible de la Modernidad, también toma parte, se convierte en parte exclusiva al transformar sus formulaciones, sus conceptos estéticos y los principios artísticos, en ideales y valores. Con su prescripción de la libertad artística como valor irrevocable determina al resto de nociones a ir a la zaga de tal valor y a imbuirse de él. Además, de acuerdo con el análisis de Rancière sobre la estética como régimen de identificación del arte, podemos afirmar que la conversión de conceptos en valores está relacionada con el carácter mismo de ese régimen estético, está motivado por él. Es decir, que la contradicción básica del régimen estético determina el carácter normativo y axiológicamente determinado de la estética.

\section{Bibliografía}

Adorno, Th. W. (2004 [1970]), Teoría estética (Obra completa, 7), trad. J. Navarro Pérez, Madrid.

Adorno, Th.; Horkheimer, M. (2001 [1947]): Dialéctica de la Ilustración, trad. J. J. Sánchez, Madrid, Trotta.

Badiou, Alain (2009 [1998]), Pequeño manual de inestética, trad. L. Vogelfang, J. Caputo, M. Burello y G. Molina, Buenos Aires, Prometeo Libros.

Bourriaud, N. (2007), Estética relacional, trad. C. Beceyro y S. Delgado, Buenos Aires, Adriana Hidalgo.

Brecht, B. (2004 [1957]), Escritos sobre teatro, trad. G. Dieterich, Barcelona, Alba.

Bullough, E. (1997), La Distanza Psichica come fattore artistico e principio estetico, trad. G. Compano, Barcelona, Alba ["'Psychical Distance' as a Factor in Art and an Aesthetic Principle”, en The British Journal of Psychology, v (1912), pp. 87-118].

Danto, A. C. (2013 [1997]), Después del fin del arte. El arte contemporáneo y el linde de la historia, trad. E. Neerman, Barcelona, Paidós.

Greenberg, C. (2002 [1936-1961]), Arte y cultura. Ensayos críticos, trad. J. G. Beramendi y D. Gamper, Barcelona, Paidós.

González Panizo, J. (2013), Jacques Rancière: estética y política, Madrid, Eutelequia.

Hegel, G. W. F. (2006 [1807]), Fenomenología del espíritu, trad. de M. Jiménez Redondo, Valencia, Pre-Textos.

Infante del Rosal, F. (2015), "Las tres estéticas y el límite", en Estudios Filosoficos, 2015, vol. 64. n. 185. pp. 35-48. 
Rancière, J. (2014a), Aisthesis. Escenas del régimen estético del arte, trad. M. Manrique, H. Marturet. Santander, Shangrila [Aisthesis. Scènes du régime de esthétique de l'art, Galilée, 2011].

Rancière, J. (1991), Breves viajes al país del pueblo, trad. I. Agoff, Buenos Aires, Nueva Visión [Courts Voyages au Pays du peuple, Le Seuil, 1990].

Rancière, J. (2012a), El desacuerdo. Política y filosofía, trad. H. Pons, Buenos Aires, Nueva Visión [La Mésentente, Galilée, 1995].

Rancière, J. (2011), El destino de las imágenes, trad. P. Bustinduy Amador, Nigran (Pontevedra), Politopías [Le Destin des images, La Fabrique, 2003].

Rancière, J. (2010a), El espectador emancipado, trad. A. Dilon, Castellón, Ellago [Le spectateur émancipé, La Fabrique, 2008].

Rancière, J. (2010b), El maestro ignorante. Cinco lecciones sobre la emancipación intelectual, trad. N. Estrach, Barcelona, Laertes [Le Maître ignorant: Cinq leçons sur l'émancipation intellectuelle, Fayard, 1987].

Rancière, J. (2012b), El malestar en la estética, trad. M. A. Pettrecca, L. Vogelfang y M. G. Burello, Madrid, Clave Intelectual [Malaise dans l'esthétique, Galilée, 2004].

Rancière, J. (2014b), El reparto de los sensible. Estética y política, trad. M. Padró, Buenos Aires, Prometeo [Le Partage du sensible, La Fabrique, 2000].

Rancière, J. (2013), Figuras de la historia, trad. C. González, Buenos Aires, Eterna Cadencia [Figures de l'histoire, Presses Universitaires de France, 2012].

Rancière, J. (2010c), La noche de los proletarios. Archivos del sueño obrero, trad. E. Bernini y E. Biondini, Buenos Aires, Tinta Limón [La Nuit des prolétaires: Archives du rêve ouvrier, Fayard, 1981].

Rancière, Jacques (2005), Sobre políticas estéticas, trad. M. Arranz, Barcelona, Universitat Autònoma de Barcelona.

Rancière, Jacques (2012c), Diálogos con Jacques Rancière, 31 de octubre de 2012 en la Universidad Nacional de Colombia, Bogotá, Canal Capital. [https:/www.youtube.com/ watch?v=KmWLRJ_taW4 Consultado en línea: 5 de abril de 2015]

Schaeffer, Jean-Marie (2005 [2000]): Adiós a la estética, trad. J. Hernández, Madrid, Machado Libros [Adieu a l'esthétique, Presses Universitaires de France, 2000]. 